\title{
Failure Investigator Mentors Needed
}

\author{
Daniel J. Benac
}

Published online: 8 December 2012

(C) ASM International 2012

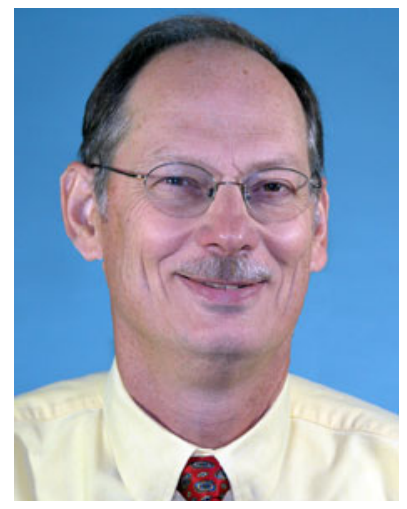

There is a need to mentor young, inexperienced engineers who want to become failure analysts or investigators. Those making a career change or new college graduates beginning their careers in failure analysis and investigation are eager and educated, yet they often lack the experience to know how to think critically, how to perform certain investigative tasks, how to interpret failure features, and how to communicate effectively. They may get on-the-job training-but without an experienced mentor, the eager engineer may end up frantically swimming to avoid sinking. Without a mentor, he or she may even drown in the process of learning or become worn out and give up-or even as devastating become a poor investigator.

What is mentoring? Our English word "mentor" comes from Greek mythology-Méntōr was a trusted advisor and teacher of the son of Odysseus. A mentor is now defined as "someone who imparts wisdom to and shares knowledge

D. J. Benac $(\bowtie)$

Baker Engineering and Risk Consultants, Inc. (BakerRisk), 3330 Oakwell Court, Suite 100, San Antonio, TX 78218, USA e-mail: dbenac@bakerrisk.com with a less experienced colleague." To mentor someone means imparting your knowledge so that they can benefit from your experience. An experienced and competent failure analyst and investigator can mentor inexperienced investigators to help them become good failure analysts and investigators.

Those of us who have had long, broad, and successful careers can reflect back and be thankful and appreciative to those who took the time and had the patience to mentor us. Now we can look to the future and put into practice what others have done for us, by taking the time to mentor someone else.

What should an experienced investigator pass on to the new investigator? I propose the following four lessons that an experienced failure investigator mentor can model and teach:

(1) How to perform tasks proficiently,

(2) How to think critically and scientifically,

(3) How to interpret physical features correctly, and

(4) How to communicate effectively.

\section{Lesson 1: How to Perform Tasks Proficiently}

Investigators need to learn how to conduct an investigation. For example, how does a metallographer learn the art of polishing soft coppers or thermally sprayed parts? Yes, there are manuals and procedures that can be read, but the skill and art comes from being shown how to do it-where to section a sample - what to cut with-how fast to cut- to use or not use cutting fluid-what grit of paper to use and for how long to polish? The metallographer learns the art through someone teaching him how to do it. Failure investigators need to be shown how to observe physical 
evidence, how to take pictures, how to operate equipment, how to document features, and finally how to write reports that communicate their findings. Then, they can gather the important facts to know what happened.

\section{Lesson 2: How to Think Critically and Scientifically}

Investigators need to learn how to think critically and with a scientific basis. Parents will often mentor, train, disciple, and educate children so that their children will know the difference between right and wrong. Having four children myself, my wife Dianne and I have considered how we want to teach our children to think. Parents want their children to make good decisions and learn how to think when faced with challenging and difficult life situations that they will face. Similarly, investigators face difficult situations and need to learn how to think critically through the issues, know what questions to ask, learn deductive and inductive reasoning, and to put into practice the scientific methods they have been trained in to solve the problem at hand. There is a debt I owe to those who taught me to think critically in order to determine the origin of a failure and to scientifically pursue how something failed mechanistically. And most importantly, they taught me how to diligently pursue the science and facts to understand what happened, which is paramount before you can determine why something failed, cracked, corroded, or exploded.

\section{Lesson 3: How to Correctly Interpret Physical Features}

Investigators need to learn how to interpret physical evidence. Experienced investigators have learned the skill of what to observe, and also to understand what those observations mean and do not mean. (Of course, two experts may have a difference of opinion, but that is another editorial).

Telling someone how to do something is not enough. For example, you could show someone how to drive a car, but if that person does not recognize the signs of running out of gas or what a red engine light means, then the driver could incorrectly interpret the physical signs with undesirable results (I recall my first job out of college while working as a failure analyst when I burned up an engine on my new 1978 Monte Carlo because I did not heed the red engine light).

A valuable tool used by investigators to interpret features is a scanning electron microscope (SEM). Thirty years ago, someone trained me how to operate a SEM, which involved learning how to turn up the beam current and saturate the filament, learning the theory and fundamentals of specimen beam interactions and how electrons and $\mathrm{x}$-rays are collected, among other things. Although the SEM equipment is very powerful and can discern the finest of features, it requires a knowledgeable investigator who can also interpret what those raster images mean. Throughout my career, I have spent many hours learning from others what the SEM images represent for a certain feature. Thirty years after my first encounter with a SEM, I had the opportunity to train two eager mechanical engineers who had limited exposure to operating a SEM. The young engineers learned how to operate the scope, but even more valuable, they learned what the images meant as otherwise unknown features would raster across the screen. They now are very proficient at obtaining meaningful images. Thirty years later, the value of the mentoring I received is very evident. Mentoring provided me (the mentor) the opportunity to pass on to others (mentees) what had been passed on to me (a former mentee)-I passed on what physical features meant.

\section{Lesson 4: How to Communicate Effectively}

Investigators need to learn effective verbal and written communication skills. Sometimes investigators have to be diplomatic and speak carefully, and at other times, they need to be forthright, proclaiming what is true even though it may not be popular. Through their experience, the seasoned investigator can help the learner to know when to speak softly and when to speak boldly. In addition, investigators need to write reports that are clear and accurate, providing detailed observations and interpretations and conclusions. Very few investigators begin as gifted writers. Most failure investigators, like me, have to learn how to write-and continue to learn how to write better. While writing this article, I recall the efforts of many who redmarked my drafts, used "White-out" on my early manuscripts, and today, use electronic-tracked changes on my documents. Although painful and very time consuming, the end result was always a better document. Young investigators need to know what to write (using good grammar and punctuation) and how to tell the investigative story. Good writing comes through practice, but can be greatly enhanced by mentoring of the budding "storyteller of truth." Without effective mentoring in communication, young investigators will not communicate accurately the story of what happened and how to prevent failure from occurring again.

The Failure Analysis and Prevention Journal publishes many articles, case histories, and lessons learned to pass understanding on to others. While this provides a valuable resource, an even more effective learning experience is obtained through mentorship with an experienced investigator sitting down together with the young investigator observing features in a microscope, thinking scientifically through the issues while wrestling with what the results mean, and then mutually deciding how to communicate 
those findings effectively to a customer, boss, a plant manager, or maybe an attorney.

As someone who may be inexperienced or starting out in their career, you need to be courageous and seek out guidance or advice from a senior person in your organization or at another company. Ask the person, "Can you explain in greater detail what this feature means?" As more experienced or senior engineers, you should not wait for someone to come to you with questions. Instead, invite them for a discussion on projects they are working on, or ask them about issues they may be having. For those of you who are mentoring, keep mentoring!! The world needs more people like you. For those who are not-what prevents you from spending the time to mentor someone? 